Jpn. J. Genet. (1983) 58, pp. 497-504

\title{
Genetic analysis of the interspecific difference in the bristle number of the sixth sternite of males in drosophila auraria complex.
}

I. Bristle counts and hybridization experiment

\author{
By Takumi HaRA and Haruo Kurokawa \\ Institute of Biological Sciences, Tsukuba University \\ Sakura-Mura, Ibaraki 305
}

(Received April 13, 1983)

\begin{abstract}
Bristle counts of the sixth sternites of males were performed for four related species of Drosophila auraria complex. Drosophila auraria male has about 14 bristles. Drosophila triauraria and $D$. quadraria have about 13 and 12 bristles, respectively. Drosophila biauraria has generally none. The difference found in the mean bristle counts was statistically significant between species.

Wild type strains of $D$. auraria and $D$. biauraria were hybridized and males of the $F_{1}$ and the backcrossed progenies were compared as concerned with their sternite bristles. It was found that the $\mathrm{X}$ chromosome and the autosome(s) were both responsible for the manifestation of the sternite bristles.
\end{abstract}

\section{INTRODUCTION}

Drosophila auraria species complex consists of four closely related species which have close resemblance in morphology. Drosophila auraria, D. biauraria, and D. triauraria are widely distributed in Japan and Korea (Kurokawa 1967; Okada 1956) but $D$. quadraria is recorded from only Formosa (Lee 1974). They are characterized by having specific features on the sixth sternites of males so that identification of specimen has firstly been made by precise comparison of this trait (Kurokawa 1956) as well as the reproductive organs of both sexes (Okada 1954). Since interspecific reproductive isolation is not complete under laboratory condition (Grossfield 1977; Kurokawa 1960; Kurokawa et al. 1982; Lee 1974), this coherent group of species are employable as a good material serving several genetic approaches for elucidation of speciation problem. Kurokawa (1962) has examined several strains of two species of this group by means of comparative morphology of the sixth sternites of males and suggested that the bristle numbers were of genetic control. The purpose of the present study is to investigate the sixth sternite bristles in all four species of this group and to analyze the basic pattern of inheritance in the sternal difference between D. auraria and $D$. biauraria. 


\section{MATERIALS AND METHODS}

Wild strains used for the bristle counts were as follows:

D. auraria: A1 (Otsuka, Tokyo); A2 (Masukatayama, Kanagawa pref.); A3 (Mitsutoge, Yamanashi pref.); A4 (Kakumazawa, Nagano pref.); A5 (Mitsutoge, Yamanashi pref.); A10 (Masukatayama, Kanagawa pref.)

D. biauraria: B578 (Shima-Onsen, Gunma pref.): B579(Shima-Onsen, Gunma pref.); B580 (Shima-Onsen, Gunma pref.); B593 (Hanamaki, Iwate pref.); B594 (Hanamaki, Iwate pref.); B595 (Hanamaki, Iwate pref.)

D. triauraria: T3 (Tsuru, Yamanashi pref.); T101 (Hirogawara, Yamanashi pref.); T488 (Nippara, Tokyo); T494 (Nippara, Tokyo); T507 (Ohomachi, Ibaraki pref.); T510 (Tateyam, Chiba pref.)

D. quadraria: Q1 (Chitou, Formosa, Texas stock 3075.1)

Total 200 male flies for each strain aged for more than one day were examined for the bristle number.

As to hybridization experiment, D. auraria (A13, Nippara, Tokyo) and $D$. biauraria (B18, Nippara, Tokyo) were reciprocally crossed and the $F_{1}$ hybrid females were backcrossed to both parental males. The bristle number was counted for total 200 males for each of the parental strains, two kinds of the $F_{1}$ hybrids, and four kinds of the backcrossed progenies. In every cross, 30 young females and males were put together in a vial and transferred every three days to a new vial.

Corn meal, ebios, molasses, and agar were used for culture medium to which sufficient yeast was added during the larval period. Flies were all reared at $25 \pm 1^{\circ} \mathrm{C}$ during the course of the experiments.

\section{RESULTS}

\section{Bristle counts in wild males of D. auraria complex}

The distributions and the mean numbers of the bristles of the three species other than D. biauraria were shown in Figure 1 and Table 1 . In D. auraria overall mean number was $14.21 \pm 0.08$, ranging from 5 to 25 as specimens examined. Among the strains examined the lowest mean was $12.64 \pm 0.17$ (A3) and the highest was $16.56 \pm 0.18$ (A4). The overall mean of $D$. triauraria was $13.29 \pm 0.08$, ranging from 5 to 22 . The lowest mean was $11.39 \pm 0.18$ (T488) and the highest was $15.56 \pm 0.17$ (T3). The ranges of the bristle counts were similar between these two species but their overall means were significantly different $(\mathrm{p}<0.001)$. The results presented in this study were almost consis- 


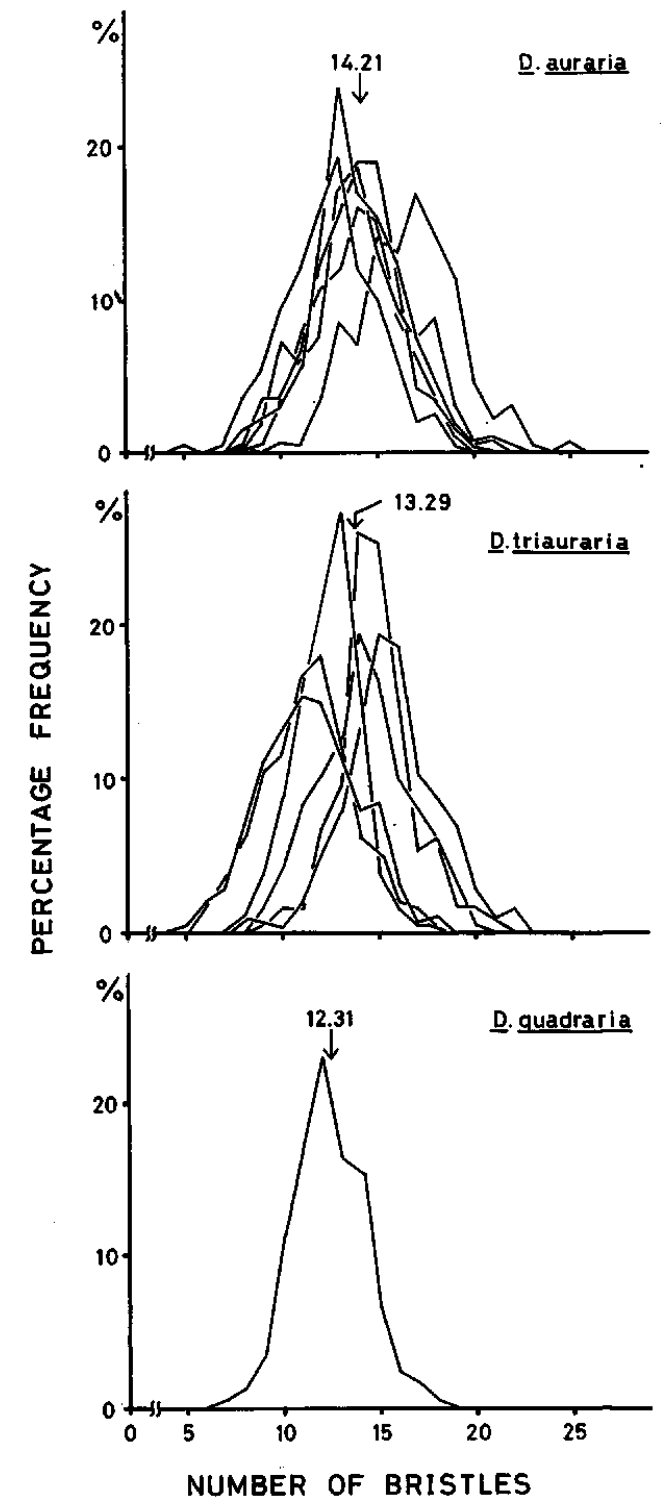

Fig. 1. Distribution of the bristle numbers in the males of wild strains of D. auraria, D. triauraria, and D. quadraria. Each line corresponds to a strain. Arrows indicate the overall means.

tent with those reported by Kurokawa (1962). So far as only strain of Q1 was examined, the mean number of $D$. quadraria was $12.31 \pm 0.13$, ranging from 7 to 18 . This mean was significantly smaller than that of $D$. triauraria $(\mathrm{p}<0.001)$.

The results of the bristle counts of $D$. biauraria were shown in Table 2. 
Table 1. Bristle numbers on the sixth sternite in the males of wild strains of D. auraria, D. triauraria, and D. quadraria

\begin{tabular}{lccc}
\hline \hline species & strain & $\begin{array}{c}\text { number of bristles } \\
\text { (mean } \pm \text { S. E.) }\end{array}$ \\
\hline & A & 3 & $12.64 \pm 0.17$ \\
D. auraria & A & 2 & $13.85 \pm 0.16$ \\
& A & 5 & $13.86 \pm 0.14$ \\
& A & 10 & $13.94 \pm 0.19$ \\
& A & 1 & $14.43 \pm 0.18$ \\
& A & 4 & $16.56 \pm 0.18$ \\
& overa11 & $14.21 \pm 0.08$ \\
\hline D. triauraria & T 488 & $11.39 \pm 0.18$ \\
& T 510 & $11.48 \pm 0.17$ \\
& T 101 & $12.29 \pm 0.12$ \\
& T 494 & $14.25 \pm 0.17$ \\
& T 507 & $14.81 \pm 0.14$ \\
& T 3 & $15.56 \pm 0.17$ \\
D. quadraria & overa11 & $13.29 \pm 0.08$ \\
\hline
\end{tabular}

200 flies were counted for each strain.

Table 2. Frequency distribution and the mean of the bristle numbers in the males of the wild strains of $D$. biauraria

\begin{tabular}{rrrrrr}
\hline & \multicolumn{5}{c}{ number of bristles } \\
\cline { 2 - 4 } strain & \multicolumn{1}{c}{$0(\%)$} & $1(\%)$ & $2(\%)$ & $3(\%)$ & mean \pm S. E. \\
\hline B 580 & 100.0 & & & $0.00 \pm 0.00$ \\
B 578 & 99.5 & 0.5 & & & $0.01 \pm 0.01$ \\
B 595 & 99.5 & 0.5 & & & $0.01 \pm 0.01$ \\
B 579 & 98.0 & 2.0 & & & $0.02 \pm 0.01$ \\
B 593 & 96.5 & 3.0 & 0.5 & & $0.04 \pm 0.02$ \\
B 594 & 91.0 & 8.0 & 0.5 & 0.5 & $0.11 \pm 0.03$ \\
overa11 & 97.4 & 2.3 & 0.2 & 0.1 & $0.03 \pm 0.01$ \\
\hline
\end{tabular}

200 flies were counted for each strain.

Kurokawa (1956) reported that male of this species has no bristle on the sixth sternite. It was, however, cleared by our counting for 1200 male flies that a few number of the specimens $(2.6 \%$ on an average) represented only few bristles being never exceeded 3. The percentage of such flies varied from 0 to 9 as strains examined. 


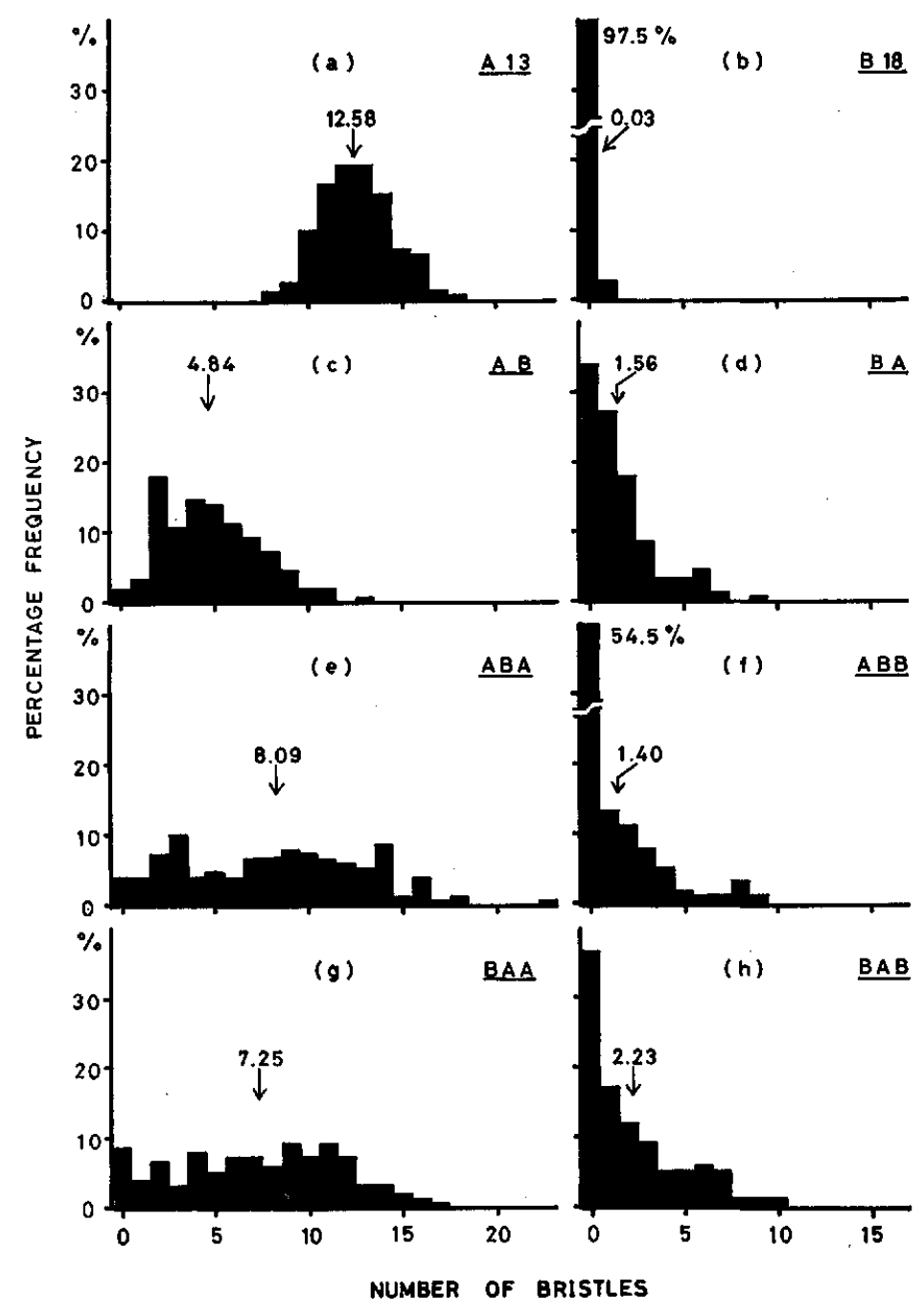

Fig. 2. Distribution of the bristle numbers in the males of $D$. auraria (A13), $D$. biauraria (B18), and their hybrids. $(\mathrm{AB}): \mathrm{A} 13$ 우 $\times \mathrm{B} 18$ 令 $\rightarrow \mathrm{F}_{1},(\mathrm{BA}): \mathrm{B} 18$ 우 $\times \mathrm{A} 13$ 응 $\rightarrow$ $\mathrm{F}_{1},(\mathrm{ABA}):\left(\mathrm{A} 13\right.$ 우 $\times \mathrm{B} 18$ 숭)우 $\times \mathrm{A} 13$ 令 $\rightarrow \mathrm{BC}_{1},(\mathrm{ABB}):(\mathrm{A} 13$ 우 $\times \mathrm{B} 18$ 송 $)$ 우 $\times \mathrm{B} 18$ 숭 $\rightarrow \mathrm{BC}_{1}$,

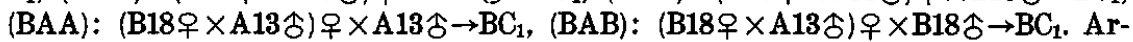
rows indicate the means.

\section{Bristle counts in hybrid males between $D$. auraria and D. biauraria}

Strains used for the interspecific crosses were A13 for D. auraria and B18 for $D$. biauraria. The distribution and the mean number of the bristles of the parental strains and of the six kinds of the hybrid progenies were shown in Figure 2 and Table 3. The mean number of A13 was 12.58土0.14, ranging from 8 to 18 (Fig. 2-a). In B18 almost all individuals have no bristle, accor- 
Table 3. Bristle numbers in the males of D. auraria $(A 13)$, D. biauraria (B18) and their hybrids

\begin{tabular}{|c|c|c|}
\hline cross & \multirow{2}{*}{ designation } & \multirow{2}{*}{$\begin{array}{c}\text { number of bristles } \\
(\text { mean } \pm \text { S. E. })\end{array}$} \\
\hline 우 & & \\
\hline $\mathrm{A} 13 \times \mathrm{A} 13$ & & $12.58 \pm 0.14$ \\
\hline B $18 \times$ B 18 & & $0.03 \pm 0.01$ \\
\hline $\mathrm{A} 13 \times \mathrm{B} 18$ & $\mathrm{AB}$ males & $4.84 \pm 0.18$ \\
\hline B $18 \times A 13$ & BA males & $1.56 \pm 0.13$ \\
\hline$(\mathrm{A} 13 \times \mathrm{B} 18) \times \mathrm{A} 13$ & ABA males & $8.09 \pm 0.34$ \\
\hline$(\mathrm{B} 18 \times \mathrm{A13}) \times \mathrm{A} 13$ & BAA males & $7.25 \pm 0.31$ \\
\hline$(\mathrm{A} 13 \times \mathrm{B} 18) \times \mathrm{B} 18$ & ABB males & $1.40 \pm 0.15$ \\
\hline$(\mathrm{B} 18 \times \mathrm{A} 13) \times \mathrm{B} 18$ & BAB males & $2.23 \pm 0.18$ \\
\hline
\end{tabular}

200 flies were counted for each mean value.

dingly, the average number became $0.03 \pm 0.01$ (Fig. 2-b). The distribution pattern in the bristles of the $F_{1}$ males was intermediate between those of the parental strains, but there appeared a large difference in the bristle counts between the reciprocal crosses (Fig. 2-c, d). The mean of the $F_{1}$ males from the cross, A13 females with B18 males (designated as AB males) was 4.84 0.18 while the mean of those from the reciprocal cross (BA males) was $1.56 \pm$ 0.13. The chromosome constitutions in these two kinds of the $F_{1}$ male zygotes were different only for $\mathrm{X}$ chromosome, that is, $\mathrm{AB}$ males received an $\mathrm{X}$ chromosome from the mother of $D$. auraria, while BA males received that from $D$. biauraria. Therefore, the $\mathrm{X}$ chromosome of $D$. auraria was considered to have an effect to manifest approximately 3 bristles exceeding that of $D$. biauraria. But a cytoplasmic effect for the sternal difference has not been distinguished as yet. $A B$ males which should have the same $X$ chromosome as A13 represented the mean of 4.84, being decreased by 7.74 from that of A13 males (Fig. 2-a, c). Thus, it was inferred that the sternal difference between the species was mainly ascribed to the autosomal role.

The distribution pattern of the bristle numbers of the male progenies of the backcross of $\mathrm{AB}$ females with $\mathrm{A} 13$ males (ABA males) were similar to those of the backcross of BA females with A13 males (BAA males), excepting for the slight difference in the means. These distribution curves were continuously ranging from 0 to 18, without a distinct mode (Fig. 2-e, g). The both kinds of the male progenies (ABB and BAB males) from the backcrosses of $F_{1}$ females with $\mathrm{B} 18$ males showed similar distribution patterns. In either case, the L-type distribution was represented, in which the bristle numbers ranged from 0 to 10 (Fig. 2-f, h). 


\section{DISCUSSION}

The sixth sternite bristle is most interesting character as it primarily relates to the sternal evolution in Drosophila. Wheeler (1960) suggested that the more advanced species in the Drosophilidae has the less number of sternites and that the reduction of a sternite has followed a sequence; firstly loss of bristles, secondly loss of sclerotized plate, and lastly loss of sternal sensilla. It can thus be concluded that the interspecific difference in the bristle number is indicative of a process of the sternal modification in $D$. auraria complex. Male flies of $D$. auraria, $D$. triauraria, and $D$. quadraria have about 14,13 , and 12 bristles on the sixth sternites, respectively, while males of $D$. biauraria have generally none: Kurokawa $(1956,1959,1960,1962$, $1963,1967)$ carried out a series of studies concerning speciation in D. auraria complex, except in D. quadraria. His works were regarded in several fields, such as, distribution, morphology, reproductive isolation, food habits, and others. According to the results obtained he concluded that $D$. auraria was the most primitive form, and reversely, $D$. biauraria was the most advanced one among the three species. Lee (1974) further studied on this complex by adding $D$. quadraria which was recently described by Bock and Wheeler (1972) and supposed that this species was the ancestral form of the all four species of this complex. In either case, the species having sixth sternite without bristles could be considered to have derived from the species having sternite bristled. In this respect, the evolutionary lineage proposed by these authors are both coincident with the Wheeler's suggestion in the family Drosophilidae (1960).

The analysis by means of hybridization experiments revealed the genetic base of the sternal difference of the males between D. auraria and D. biauraria. In D. busckii, Hihara (1975) discovered a major dominant factor being responsible for bristle manifestation in the first sternite. It is not likely in $D$. auraria complex that the sternal bristles are manifested by such a single factor. If only one locus could fully be responsible for this difference, the sternal characters should distinctly be segregated as the gene combinations in the progenies, allowing for small deviation introduced by chance. However, as shown in Fig. 2 the distribution pattern of the backcrossed progenies are obviously continuous through all the individuals. It can thus be assumed that the number of the loci for the bristle manifestation is at least more than two.

From the comparison of the mean bristle numbers represented in the males of the both parental species and the hybrids, the contributions of the $\mathrm{X}$ chromosome and the autosome(s) to this character can be assumed to approximate to 3 and 8 bristles, respectively. The autosomal contribution thus amounts to more than twice as much as that of the $\mathrm{X}$ chromosome. A probable effect of the cytoplasm might be confused with the contribution by the 
$\mathrm{X}$ chromosome. This problem will be solved by further analysis in detail by using chromosomes marked with mutant genes.

We thank National Institute of Genetics in Japan for kind providing the strain of D. quadraria.

\section{REFERENCES}

Bock, I. R. and WHEELER, M. R. (1972) The Drosophila melanogaster species group. Univ. Texas Publ. 7213, 1-102.

Grossfield, J. (1977) Sexual isolation between $D$. auraria and D. quadraria. Dros. Inf. Ser. $52,125$.

HiHARA, F. (1975) Mechanism for reduction of the first sternal bristles in Drosophila busckii. Bulletin of Liberal Arts and Education, Dokkyo Univ. 9, 23-64.

KUROKAWA, H. (1956) Comparative studies on some characteristics of three races of Drosophila auraria. Ann. Zool. Jap. 29, 225-233.

KuROKAWA, H. (1959) Experiments on sexual isolation between races A and B of Drosophila auraria. Ann. Zool. Jap. 32, 220-224.

Kurokawa, H. (1960) Sexual isolation among the three races, A, B and C of Drosophila auraria. Jpn. J. Genet. 35, 161-166.

KuRoKaWA, H. (1962) Population genetics on three races of Drosophila auraria Peng. I. Bristle number of sixth sternite in male. Jpn. J. Genet. 37, 510-517.

KuroKaWA, H. (1963) Population genetics on three races of Drosophila auraria Peng. II. Sexual isolation among strains within a race C. Jpn. J. Genet. 38, 1-5.

KuroKawa, H. (1967) Population genetics on three races of Drosophila auraria Peng. III. Geographical and ecological distribution of the races, A, B and C, with special regard to its speciation. Jpn. J. Genet. 42, 109-119.

KuroKawa, H., OGUMA, Y.and Tachibana, N. (1982) Sexual isolation among four species of $D$. auraria complex. Dros. Inf. Ser. 58, 98-99.

LEE, T. J. (1974) Speciation in the species complex Drosophila auraria. Jpn. J. Genet. 49, 305 (abstract in Japanese).

OKadA, T. (1954) Comparative morphology of the Drosophilid flies. I. Phallic organs of the melanogaster group. Konty $\hat{u} 22,36-46$.

OKADA, T. (1956) Systematic study of Drosophilidae and allied families of Japan. Gihôdô Co. Ltd., Tokyo, pp. 119-121.

WHEELER, M. R. (1960) Sternite modification in males of the Drosophilidae (Diptera). Ann. Entmol. Soc. Amer. 53, 133-137. 